\title{
Segundas residências turísticas litorâneas no Brasil: uma análise bibliométrica da produção científica de 1990 a 2017
}

\author{
Second home tourism on the Brazilian coast: a bibliometric analysis of the scientific production \\ from 1990 to 2017
}

\author{
Bruna Carolina Cardoso ${ }^{1}$ \\ Cinthia Maria de Sena Abrahão
}

\begin{abstract}
Resumo
As produções científicas constituem o veículo pelo qual o conhecimento é difundido e democratizado, traduzindo-se como respostas para os problemas que permeiam a sociedade. Cada área de estudo apresenta distintas especificidades e níveis de maturidade concernentes à essas produções, tanto em termos qualitativos como quantitativos. Nesse sentido, a bibliometria emerge como uma importante ferramenta de pesquisa para sistematizar informações e acompanhar o desenvolvimento de determinados campos do saber, destacando indicadores de produção. Isso pode evidenciar tendências, dispersões e obsolescências das vertentes científicas, servindo como contributo para subsidiar a construção de novas pesquisas. O presente artigo tem como objetivo central apresentar os resultados obtidos por meio do levantamento bibliométrico das publicações acadêmicas relativas ao turismo de segunda residência no litoral brasileiro. As residências secundárias evidenciam crescente relevo nas discussões acadêmicas hodiernas, em função dos impactos por elas projetados nos aspectos territoriais das localidades, em contextos de grande fortalecimento da atividade turística cuja fruição não se dá de modo universal. O território, como elemento que transcende a mera expressão material, sofre determinadas reconfigurações que podem se delinear sob uma lógica assimétrica, principalmente no que tange às relações de poder. Os principais resultados demonstraram que há um número expressivo de trabalhos sobre a temática em questão os quais apresentam pluralidade de indicadores, todavia, identificou-se lacunas nas classificações metodológicas que dificultaram a análise.
\end{abstract}

Palavras-chave: Turismo. Bibliometria. Território. Segundas residências. Litoral brasileiro.

\begin{abstract}
Scientific production is the vehicle through which knowledge is disseminated and democratized, translating the problems that permeate society into answers. Each study area presents different qualitative and quantitative specificities and levels of maturity concerning these productions. Thus, bibliometrics emerges as an important research tool to systematize information and to monitor the development of certain fields of knowledge, highlighting production indicators. This can highlight tendencies, dispersions and obsolescence of the scientific aspects, in order to contribute to subsidize the construction of new researches. The main objective of this article is to present the results obtained through the bibliometric survey of the academic publications related to the tourism of second residence in the Brazilian coast. Secondary residences show increasing importance in current academic discussions, due to the impacts they projected in the territorial aspects of localities, in contexts of great strengthening of tourism activity whose enjoyment does not occur in a universal way. Territory, as an element that transcends mere material expression, undergoes certain

\footnotetext{
${ }^{1}$ Graduanda do curso de Gestão e Empreendedorismo da Universidade Federal do Paraná - Setor Litoral. Bolsista de Iniciação Científica PIBIC. E-mail: brunage2015@gmail.com

${ }^{2}$ Doutora em Geografia pela Universidade Federal do Paraná. Professora Permanente do Programa de Pós-Graduação em Desenvolvimento Territorial Sustentável (PPGDTS) da UFPR. E-mail: cisena01@ gmail.com
} 
reconfigurations that can be delineated under an asymmetric logic, especially with regard to relations of power. The main results showed that there is a large number of papers on this subject, which present a plurality of indicators. However, there were gaps in methodological classifications that made the analysis difficult.

Keywords: Tourism. Bibliometrics. Territory. Second homes. Brazilian Coast.

\section{Introdução}

O turismo constitui em fenômeno de caráter pluridimensional, cuja existência não raro molda as configurações políticas, socioeconômicas, territoriais e ambientais das regiões que nele alicerçam a sua economia. Para Medina (2012), na sociedade pós-industrial tal fenômeno adquire relevância inconteste, uma vez que valoriza simbolicamente os espaços urbanos e naturais, movimenta o capital, além de promover a heterogeneidade cultural. Trata-se de um fenômeno que apresenta complexidades singulares face à diversidade de agentes que atuam na sua construção, os quais são conduzidos por lógicas e racionalidades específicas. O turismo desenvolve-se sob o influxo de determinações locais, estaduais e federais, o que evidencia o forte cunho sistêmico que o caracteriza.

Em função dessa pluralidade de ingerências que se desdobram nos territórios turísticos, estes comumente são marcados por inúmeras contradições e conflitos de interesse. Nesse sentido, faz-se mister compreender o espaço como algo socialmente produzido e permeado por relações de poder (CORIOLANO, 2006). Isto porque os territórios transcendem a mera expressão material, uma vez que são engendrados por relações sociais, especialmente relações de poder e apropriação dos espaços (HAESBAERT, 2004).

A complexidade que envolve a constituição e sustentação das significações e identidades socioterritoriais frequentemente enseja o nascimento de disputas de legitimidade em que diferentes atores esboçam ações coletivas para questionar padrões de apropriação dos territórios e a distribuição de poder entre eles. No tocante ao turismo, tais disputas assumem feições ainda mais controversas, em que pese a forte assimetria que configura a sua fruição, dadas as dissonâncias sociais vigentes em âmbito global que não oportunizam o faire un tour em distintos espaços turísticos para as classes de baixo poder aquisitivo. Deste modo, comumente se edificam concepções de que o turismo simboliza a elitização e a desigualdade social, concepções estas que se fortalecem no que diz respeito às segundas residências, as quais em geral são propriedades de indivíduos abastados e consideradas distintivas do status. Por outro lado, há aqueles que enxergam ambos os fenômenos como a redenção das economias locais. Tais extremos, todavia, requerem equilíbrio na sua análise para que não se 
degenere para a construção de visões unilaterais que não coadunem com a complexidade da realidade contemporânea (CORIOLANO, 2006; FERREIRA, 2006).

Os aspectos supramencionados denotam que as atividades turísticas relativas às segundas residências são permeadas por contradições e conflitos, bem como por aspectos que contribuem para a compreensão das diversas conformações territoriais. Tais atividades têm sido objeto de estudo das mais variadas áreas do conhecimento científico, uma vez que, apesar dos benefícios gerados por essa dinâmica no desenvolvimento local, há que se considerar os seus revérberos negativos dentro de cenários de fortes conjugações de interesses e assimetrias nas relações de poder. Esses estudos constituíram o foco central do presente levantamento bibliométrico, que teve como objetivo analisar indicadores e tendências dos estudos que se concentraram na compreensão dessa temática.

Nos tópicos a seguir encontram-se especificados uma caracterização teórica sobre segundas residências, turismo e o método bibliométrico, os percursos metodológicos da pesquisa com a pormenorização de cada etapa realizada, os resultados e discussões, considerações finais e referências.

\section{Turismo: Abordagens conceituais}

O turismo se caracteriza como o deslocamento transitório dos indivíduos para além do seu entorno habitual por períodos inferiores a um ano (UNWTO, 2007). Tal fenômeno apresenta crescente expansão na sociedade pós-industrial na qual se levantam novas possibilidades lúdicas e hedonistas, dentro de um cenário no qual são erigidas diferentes formas de uso do tempo e do espaço (TALAVERA, 2008). Essa atividade tem se fortalecido pela flexibilidade da conjuntura de trabalho atual que implica em maior liberdade de administração do tempo pessoal para o lazer. Além disso, os indivíduos têm maior acesso a melhores formas de se apropriar de coisas e sensações que outrora eram privilégios das classes abastadas (TRIGO, 1998).

Diante do crescimento vertiginoso do turismo em âmbito mundial, ocorre a saturação de inúmeros destinos e a emergência de outros, especialmente os tropicais como o Brasil, fator que enseja o fortalecimento do turismo de sol e praia (PAULA, 2012). De acordo com o Ministério do Turismo (2010) as regiões tropicais consolidaram o turismo de sol e praia na década de 70, uma vez que os processos de industrialização e melhoria nos sistemas de transporte facilitaram o acesso às cidades litorâneas. No Brasil, o segmento surge no Rio de Janeiro e se expande para outras áreas das regiões Sudeste e Sul e posteriormente para todo o litoral do país. Na atualidade, a região Nordeste 
assume grande destaque como destino turístico, em função de suas especificidades climáticas que favorecem as visitações o ano todo.

Tal vertente turística promove significativos impactos sobre as configurações regionais, uma vez que traz a necessidade de implantação de resorts, condomínios e segundas residências pela sua vinculação a políticas imobiliárias de crescimento. Esse ritmo de ocupação tem potencial de afetar comunidades locais e ambientes naturais de alta fragilidade e produtividade biológica, aspecto que pode resultar em diversas ordens de conflitos, socioespaciais, ambientais e territoriais (PEREIRA, et. al 2016).

\section{Territórios turísticos e segundas residências}

Os territórios, para que sejam compreendidos coerentemente, faz-se necessário transcender as concepções que os concebam apenas como uma expressão material, uma vez que são formados por relações sociais, em especial relações de poder e apropriação dos espaços (CORIOLANO, 2006; HAESBAERT, 2004). Haesbaert (2004) advoga que todo território carrega consigo tipologias de identificação e valorização simbólica pelos seus residentes. A identidade individual e coletiva pode ser construída a partir do território e este angaria significados através dos grupos sociais, formas de domínio, ocupação e controle. A concretização das relações econômicas e culturais e a forma pela qual os sujeitos se organizam no espaço e atribuem sentido ao lugar constituem as chamadas territorialidades.

Diante dos fatos que se materializam no cotidiano do homem, os simbolismos e significados conferidos ao território cedem espaço para desconexões identitárias, gerando os chamados nãolugares. Essa superabundância factual do mundo contemporâneo suprime identidades, relações e alimenta uma a-historicidade, realidade que não se sucedia nos lugares chamados antropológicos, nos quais identidades, relações e construtos históricos não eram aniquilados (AUGÉ, 2012).

Haesbaert e Limonad (2007) acrescentam nesse contexto que a complexificação dos territórios se vê reforçada pelos processos globalizadores, uma vez que os fenômenos que se sucedem na realidade humana estão amplamente vinculados com as redes do capitalismo planetário. Quando determinados grupos buscam antepor-se aos ditames globais, acabam ingressando em graves quadros de exclusão cultural e socioespacial. Nesse sentido, os autores asseveram que os conflitos socioespaciais e culturais que ora se desdobram derivam do fato de que a globalização privilegia 
determinados pontos do globo, ainda que se defenda que a mesma promove homogeneizações culturais, sociais e econômicas.

Nesse sentido, os avanços do capitalismo, em sua vertente global, implicam que diversos territórios deixam de configurar-se como objetos de uso para transformar-se em objetos de troca, com ampla prevalência dos interesses financeiros sobre o restante da vida social (SANTOS,1999). Quando tais ideários financeiros pautados unicamente em regras de mercado conduzem a ações irracionais, pode haver prejuízos irreparáveis a grupos humanos e regiões geográficas (TRIGO, 1998).

A complexidade que envolve a constituição de territórios permeados por aspectos financeiros, sociais e ambientais assume contornos ainda mais controversos quando se refere aos territórios turísticos. Isto porque nestes se materializam fortes conjugações de interesses que tendem a privilegiar grupos dominantes e as pretensões estatais que defendem discursos pró-crescimento (CORIOLANO, 2006). No que tange aos destinos constituídos por segundas residências, tal realidade se vê agravada pela intrínseca relação que essa dinâmica possui com a posse e o uso da terra, fator que recorrentemente gera embates entre concepções dicotômicas. Segundas residências são definidas como as habitações ocupadas esporadicamente para fins de recreação e lazer por indivíduos que possuem lares fixos em outras regiões. Constituem-se como bens de consumo de camadas sociais de médio e alto poder aquisitivo pelos custos de compra e gastos com manutenções (COTTYN, 2011).

Assis (2003) acrescenta que uma razão central para a aquisição de uma residência secundária tem sido a busca por oportunidades de investimento para o futuro. Isto porque, o investimento em terras constitui um caminho para a preservação do capital acumulado especialmente em uma economia de caráter inflacionário. Trata-se de um investimento que não oferece liquidez e rentabilidade imediatas, visto que a venda está sujeita à lei da oferta e procura e nem sempre esses imóveis são alugados ou vendidos, eventualmente permanecendo vazios grande parte do ano. Tratase igualmente de um investimento que enseja estabilidade aos fluxos do turismo pela construção de uma fidelidade do segundo residente em relação a localidade (ASSIS, 2003; MARJAVAARA, 2008).

Tais residências constituem-se como importantes contributos para o desenvolvimento local, visto que fortalecem a geração de emprego e renda, mas particularmente em função da elevação de receitas fiscais. Em contrapartida, essa dinâmica igualmente impele ao crescimento do custo de vida e dos preços da terra em virtude dos encargos fiscais que se sobrelevam em decorrência da valorização dos imóveis. Nesse sentido, destaca-se a importância da atuação dos empreendimentos imobiliários que, embora não sejam considerados como turísticos, subsidiam o funcionamento das dinâmicas turísticas locais relativas ao aluguel, compra e venda de imóveis (COTTYN, 2011). 
Outro aspecto destacado dentre os estudiosos sobre o tema das segundas residências, considerando em particular a expansão desse fenômeno no âmbito das regiões litorâneas, diz respeito ao processo de transformação social, em função do deslocamento de populações tradicionais, que ocupavam esses espaços. Coriolano (2006) destaca que as regiões litorâneas, inicialmente ocupadas pelos indígenas, pescadores, comunidades tradicionais, os chamados "povos do mar" foram desapropriadas para ceder lugar às residências secundárias, às cadeias hoteleiras, restaurantes, parques temáticos e aos grandes resorts. Dentro dessa configuração espacial, faz-se mister reconhecer a luta dos vários atores locais, como os nativos usuários do espaço costeiro, que buscam defender as suas propriedades antepondo-se aos interesses dos empresários, dos agentes imobiliários e do próprio Estado, os quais primam pelo valor de troca do espaço. Além disso, no caso de áreas campestres, pode-se ocasionar a redução de espaços destinados à agricultura e ao extrativismo, ensejando, deste modo, o fortalecimento de embates socioterritoriais.

O amaine ou agravo do panorama supramencionado dependerá da lógica e racionalidade que conduzirão as ações dos agentes tomadores de decisão, uma vez que os territórios turísticos, dentro de sua complexidade sistêmica, são permeados por ingerências de múltiplos atores (MEDINA, 2012). Importa destacar que tal fenômeno desenvolve-se sob o influxo de determinações das diversas escalas federativas, fator que evidencia o forte teor sistêmico que o caracteriza. Inobstante inexista o monopólio da atuação estatal, o Estado representa relevância inconteste nesse contexto, visto que age como regulador e regulamentador do setor, mediante elaboração de políticas de desenvolvimento com ações de planejamento, promoção e controle da atividade (OLIVEIRA; OLIVEIRA, 2012). Todavia, a atuação do Estado pode vir a apresentar graves disfunções, sendo conduzida por lógicas nebulosas e parcamente transparentes (ACSELRAD, 2010).

\section{Bibliometria}

A produção científica reveste-se de inegável importância no conjunto das atividades acadêmicas de investigação, constituindo-se como um instrumento através do qual se mostram os resultados, a pertinência e a relevância dos estudos, em que pese a forte relação existente entre o conhecimento e a informação registrada. Nesse sentido, a bibliometria surge como uma técnica quantitativa que permite mensurar índices de produção e disseminação do conhecimento, identificar as diferentes contribuições teóricas, empíricas ou metodológicas e acompanhar o desenvolvimento 
das diversas áreas científicas, revelando tendências, dispersões e obsolescências (COSTA et. al, 2012).

O termo bibliometria deriva da junção do grego biblion, que significa livro, com o latim metricus e o grego metrikos, que designam mensuração. Trata-se de um conceito, originalmente, definido como um processo de medida relativa ao livro ou ao documento (BUFREM; PRATES, 2005). Esse termo foi utilizado pela primeira vez em 1917, quando Cole e Eales publicaram uma análise estatística da história da disciplina de anatomia comparada. A bibliometria direcionava-se para a medição estatística de monografias, com utilidade destacável nas bibliotecas e rapidamente passou a contemplar a análise de outros documentos, como periódicos e artigos científicos (COSTA et. al, 2012). Para Chueke e Amatucci (2015), a bibliometria configura-se como uma importante ferramenta para endereçar problemas a serem pensados em pesquisas futuras. Os autores argumentam que a trajetória de construção do conhecimento perpassa pela identificação de progressos e lacunas, identificação esta que conduz ao aperfeiçoamento da atuação científica.

Com relação à aplicação da bibliometria no campo de estudos do turismo, destaca-se que esta tem sido aplicada sobre as temáticas diversas, tais como políticas públicas (LOPES et. al, 2011), inovações da pesquisa (BARBOSA et. al, 2008), relação entre redes (XAVIER, et. al 2012), turismo e megaeventos (SILVA et. al, 2016). O presente estudo, por sua vez, se voltou para a realização da bibliometria sobre segunda residência e sua relação com o turismo.

\section{Percursos Metodológicos}

A Bibliometria representa um procedimento metodológico relativamente novo, cujo surgimento é reconhecido no início do século XX e o desenvolvimento esteve intimamente vinculado às ciências da informação. Essa sistematização metodológica está associada à necessidade de identificação e mensuração da produção e comunicação científica, em que contou com algum marcos relevantes na sua origem, quais sejam: método de Lotka, de 1926, que se ocupa da medição da produtividade; por Bradford (1934), a lei de dispersão do conhecimento científico; e, a partir de Zipf (1949), o modelo de distribuição e frequência de palavras. Em princípio foi intitulada como Bibliografia Estatística, em função do processo de apropriação das ferramentas básicas da estatística e da matemática, assumindo o termo atual a partir da década de 1930 (ARAÚJO, 2006).

No que tange ao percurso metodológico da pesquisa, esse foi composto pelas seguintes etapas: i) definição das bases de dados e palavras-chave; ii) definição do recorte temporal e tipos de 
materiais a serem levantados e iii) definição dos indicadores a serem analisados e iv) contagem dos indicadores e análise dos dados. Segue abaixo a pormenorização de cada etapa:

Etapa i) Preliminarmente foram identificadas as principais bases de dados de estudos científicos que subsidiariam o levantamento, sendo elas o Portal de Periódicos da Capes, Scielo, Biblioteca Digital de Teses e Dissertações (BDTD) e Google Scholar. Posteriormente, foram definidas as palavras-chave e conjugações de busca: turismo, território, litoral brasileiro e segundas residências. No processo de seleção dos estudos eram separados os materiais nos quais constava o termo segundas residências no título ou no resumo.

Etapa ii) Definiu-se o recorte temporal: 1990 a 2017. Tal escolha se justifica pelo fato de que a partir de 1990 se concretizou o ' boom' do turismo no Brasil (ALBUQUERQUE, 2010), com forte especulação imobiliária se projetando sobre as principais áreas litorâneas (CORIOLANO, 2006). Posteriormente, definiu-se os materiais que seriam contabilizados, dentre os quais foram incluídas teses, dissertações, livros, monografias e artigos científicos.

Etapa iii) Foram identificadas as áreas de conhecimento de acordo com a tabela de classificação da Coordenação de Aperfeiçoamento de Pessoal de Nível Superior (CAPES) de 2014. Além disso, considerou-se como critérios de classificação dos resultados as universidades de origem da pesquisa, o ano, recorte territorial do estudo, as revistas onde foram publicadas e os procedimentos metodológicos. Os procedimentos metodológicos dos estudos foram analisados de acordo com os critérios: abordagem: (quantitativa, qualitativa ou quanti-qualitativa), classificação por objetivos (exploratória, descritiva, explicativa), por procedimentos (documental, bibliográfica, etnográfica, estudo de caso, pesquisa ação e pesquisa ex post facto) e técnicas/instrumentos utilizados, em consonância com o enquadramento teórico de Gil (2002) e Gerhardt e Silveira (2009).

Etapa iv) Os arquivos selecionados passaram por fichamentos cuja subdivisão consistiu em ano, tipo de material, áreas do conhecimento, recorte territorial, universidade da pesquisa, revistas de publicação e procedimentos metodológicos. Posteriormente, foi realizada a contagem de cada item destacado e posteriormente produziu-se tabelas e gráficos mediante utilização do Microsoft Excel. Foi analisado um total de 173 trabalhos.

\section{Resultados e discussões}

A partir do levantamento bibliométrico realizado identificou-se indicadores de produção que evidenciam o estado da arte das produções relativas às segundas residências litorâneas, os quais estão descritos a seguir. 
Inicialmente foram identificadas 207 publicações e após a seleção dos materiais segundo os critérios metodológicos, chegou-se a 173 publicações. No que se refere ao recorte temporal das produções científicas, destaca-se que entre 1990 e 2017 identificou-se variações no número de publicações. O gráfico 1 denota que em 1995 ocorreu a primeira publicação e os anos mais profícuos foram 2010, 2012, 2013, 2015 e 2017. O ano de 2012 se destaca com 22 publicações, revelando um significativo avanço em relação a 2011. No entanto, considerando o alto número de publicações de 2010 a 2016, observa-se um declínio de produção no ano de 2017, sendo este último contemplado com apenas quatro publicações.

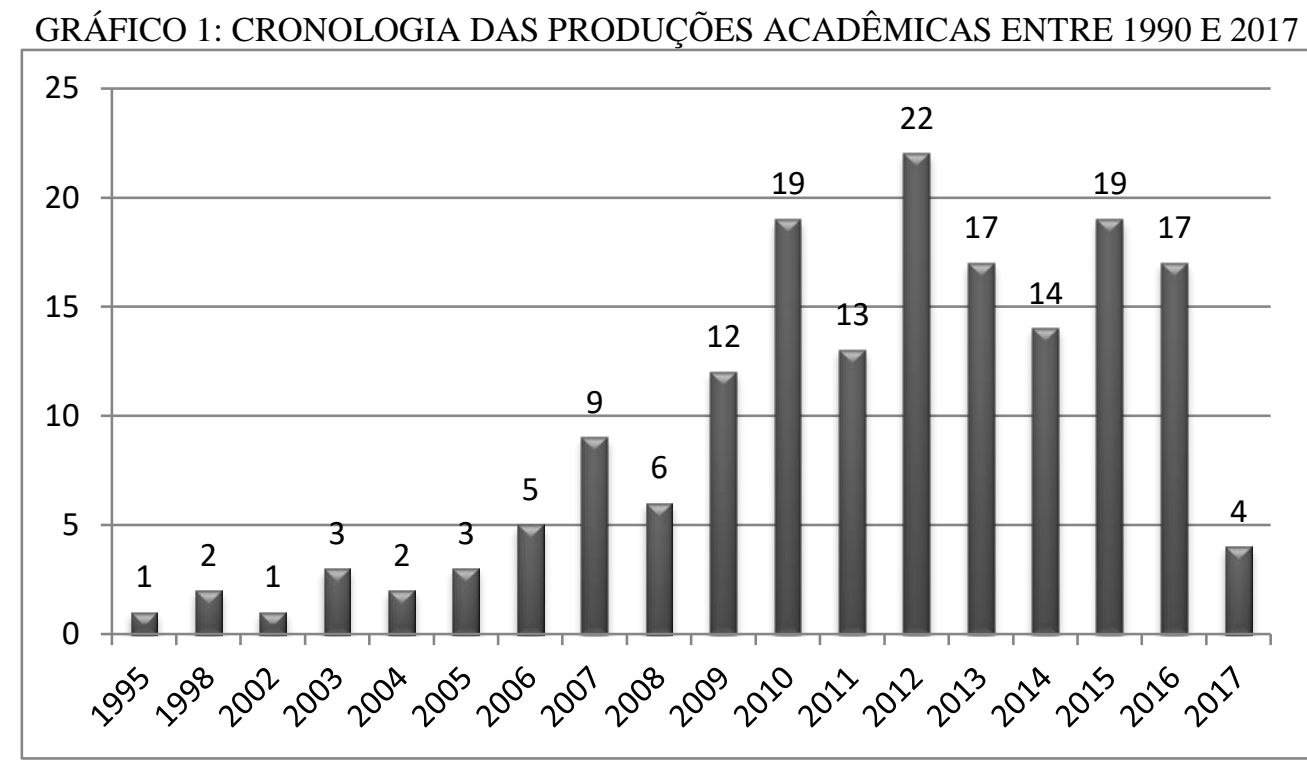

FONTE: Scielo (2017), BDTD (2017); Portal de Periódicos Capes/MEC (2017), Google Scholar (2017). Organização das autoras.

Os dados supracitados evidenciam que parte considerável das produções científicas concentrase na pós-graduação. Importa ressaltar que na tipologia artigos, 55\% deles advêm de estudos de doutorado, 38\% do mestrado e 7\% da graduação. Tal realidade corrobora as afirmações de Hilu e Gisi (2011), segundo as quais a produção científica contemporânea privilegia o enfoque na pós-graduação, ainda que haja a necessidade de se desenvolver estudos no âmbito da graduação, dada a indissociabilidade entre extensão, ensino e pesquisa.

Pode-se afirmar que o turismo de segundas residências é abordado por distintos campos de conhecimento. Há predominância de produções na área da Geografia, se considerado o volume absoluto (Tabela 2): 
TABELA 2: CLASSIFICAÇÃO DAS PUBLICAÇÕES SOBRE AS SEGUNDAS RESIDÊNCIAS DE ACORDO COM AS ÁREAS DE CONHECIMENTO DA CAPES

\begin{tabular}{c|c|c} 
Área do conhecimento & Geral & \% do total \\
\hline Geografia & 91 & $52 \%$ \\
\hline Turismo & 33 & $19 \%$ \\
\hline Arquitetura e urbanismo & 20 & $11 \%$ \\
\hline Ciências ambientais & 12 & $6 \%$ \\
\hline Administração & 4 & $2 \%$ \\
\hline Planejamento urbano e regional & 2 & $1 \%$ \\
\hline Geologia & 2 & $1 \%$ \\
\hline Ciências econômicas & 2 & $1 \%$ \\
\hline Educação & 2 & $1 \%$ \\
\hline Ciências sociais & 2 & $0,5 \%$ \\
\hline História & 1 & $0,5 \%$ \\
\hline Engenharia civil & 1 & $0,5 \%$ \\
\hline Oceanografia & 1 & Capes/MEC
\end{tabular}

FONTE: Scielo (2017), BDTD (2017); portal de periódicos Capes/MEC (2017), Google Scholar (2017). Organização: As autoras (2018)

Os estudos identificados abordaram todas as regiões litorâneas brasileiras (Tabela 3). Os pesquisadores concederam maior enfoque para a região nordeste cujas especificidades climáticas/naturais tornam o turismo altamente dinâmico, além de maior proximidade com o continente norte americano e Europeu. Nesse sentido, entende-se que também tenha se tornado mais atrativo para investimentos em segunda residência.

TABELA 3. PRODUÇÃO POR RECORTE TERRITORIAL

\begin{tabular}{l|c|c} 
Recorte territorial & Geral & \% do total \\
\hline Litoral nordeste & 114 & $65 \%$ \\
\hline Litoral sudeste & 23 & $13 \%$ \\
\hline Litoral sul & 23 & $13 \%$ \\
\hline Litoral norte & 10 & $5 \%$ \\
\hline Sem definição de recorte & 3 & $1 \%$ \\
territorial & & \\
\hline Total & 173 &
\end{tabular}

FONTE: Scielo (2017), BDTD (2017); Portal de Periódicos Capes/MEC (2017), Google Scholar (2017). Organização: As autoras (2018)

Neste contexto, destaca-se que tais produções foram desenvolvidas em sua maioria em universidades públicas, visto que $67 \%$ derivam de universidades federais, $26 \%$ de universidades estaduais e $7 \%$ de universidades privadas, dentro de um universo de 28 instituições de ensino 
identificadas ao longo do levantamento bibliométrico. No tocante aos periódicos que publicam os artigos, apenas a Revista de Geografia da UFC apresentou percentuais sutilmente mais elevados de produção (5\%) dentro de um total de 27 revistas identificadas. As outras revistas apresentavam em média apenas 1 publicação. Um total de 20 trabalhos foi apresentado em anais de eventos, com 4\% de produções no V Encontro Nacional da Anppas (Associação Nacional de Pós-Graduação e Pesquisa em Ambiente e Sociedade) ocorrido em Florianópolis/SC, no ano de 2010.

No que tange às temáticas abordadas, parcela considerável de publicações se concentrou em compreender nas dinâmicas imobiliárias e sua relação com economia e urbanização (51\%) e $24 \%$ se centrou na discussão territorial (Tabela 4):

TABELA 4: CLASSIFICAÇÃO POR TEMÁTICAS

\begin{tabular}{c|c|c|c|c} 
Territorial & $\begin{array}{c}\text { Territorial e } \\
\text { ambiental }\end{array}$ & Ambiental & $\begin{array}{c}\text { Dinâmica } \\
\text { imobiliária - } \\
\text { economia e } \\
\text { urbanização }\end{array}$ & TOTAL \\
\hline 42 & 15 & 27 & 89 & 173
\end{tabular}

FONTE: Scielo (2017), BDTD (2017); Portal de Periódicos Capes/MEC (2017), Google Scholar (2017). Organização: As autoras (2018)

Nos trabalhos selecionados foram identificadas diversas lacunas nas classificações metodológicas, uma vez que em $12 \%$ das produções havia caracterização do tipo de pesquisa utilizado, conforme demonstrado na tabela 5. Parte significativa dos pesquisadores limitou-se a descrever unicamente as ferramentas utilizadas.

TABELA 5: CLASSIFICAÇÕES METODOLÓGICAS POR TIPO DE TRABALHO

\begin{tabular}{c|c|c|c|c|c|c|c|c} 
Metodologias & Artigos & $\begin{array}{c}\text { \% do } \\
\text { total }\end{array}$ & Teses & $\begin{array}{c}\% \text { do } \\
\text { total }\end{array}$ & Dissertações & $\begin{array}{c}\text { \% do } \\
\text { total }\end{array}$ & Monografias & $\begin{array}{c}\% \text { do } \\
\text { total }\end{array}$ \\
\hline $\begin{array}{c}\text { Sem } \\
\text { classificação } \\
\text { metodológica }\end{array}$ & 35 & $20 \%$ & 3 & $1,7 \%$ & 6 & $3 \%$ & 3 & $1 \%$ \\
\hline $\begin{array}{c}\text { Classificação } \\
\text { metodológica } \\
\text { incompleta }\end{array}$ & 61 & $35 \%$ & 17 & $9,8 \%$ & 30 & $17 \%$ & - & - \\
\hline $\begin{array}{c}\text { Classificação } \\
\text { metodológica } \\
\text { completa }\end{array}$ & 7 & $4 \%$ & 2 & $1 \%$ & 6 & $3 \%$ & - & -
\end{tabular}

FONTE: Scielo (2017), BDTD (2017); Portal de Periódicos Capes/MEC (2017), Google Scholar (2017). Organização: As autoras (2018)

No que tange à classificação metodológica por abordagem, $81 \%$ das produções não a mencionaram (Tabela 6): 
TABELA 6: CLASSIFICAÇÃO METODOLÓGICA POR ABORDAGEM

\begin{tabular}{c|c|c|c|c|c} 
Tipologia & Qualitativa & Quantitativa & $\begin{array}{c}\text { Quanti- } \\
\text { qualitativa }\end{array}$ & $\begin{array}{c}\text { Abordagem não } \\
\text { mencionada }\end{array}$ & \% do total \\
\hline Artigos & 6 & 2 & 4 & 94 & $54 \%$ \\
\hline Dissertações & 5 & - & 3 & 32 & $18 \%$ \\
\hline Teses & 6 & - & 3 & 12 & $6,9 \%$ \\
\hline Monografias & - & - & - & 3 & $1 \%$ \\
\hline & & & & &
\end{tabular}

FONTE: Scielo (2017), BDTD (2017); Portal de Periódicos Capes/MEC (2017), Google Scholar (2017). Organização: As autoras (2018)

No tocante à classificação por objetivos, em $89 \%$ dos trabalhos não houve menção sobre esse aspecto (Tabela 7):

\section{TABELA 7: CLASSIFICAÇÃO METODOLÓGICA POR OBJETIVOS}

\begin{tabular}{c|c|c|c|c|c} 
Tipologia & Exploratória & Descritiva & Explicativa & Não mencionado & \% do total \\
\hline Artigos & 7 & 2 & - & 97 & $56 \%$ \\
\hline Dissertações & 3 & 1 & - & 36 & $20 \%$ \\
\hline Teses & 1 & 3 & 1 & 19 & $10 \%$ \\
\hline Monografias & - & - & - & 3 & $1 \%$
\end{tabular}

FONTE: Scielo (2017), BDTD (2017); Portal de Periódicos Capes/MEC (2017), Google Scholar (2017). Organização: As autoras (2018)

Com relação aos procedimentos, $84 \%$ dos trabalhos não evidenciaram a classificação metodológica desse aspecto (Tabela 8):

\begin{tabular}{c|c|c|c|c|c|c} 
TABELA 8: CLASSIFICAÇÃO METODOLÓGICA POR PROCEDIMENTOS \\
$\begin{array}{c}\text { Tipologia } \\
\text { Estudo de } \\
\text { caso }\end{array}$ & $\begin{array}{c}\text { Pesquisa } \\
\text { bibliográfica }\end{array}$ & Etnográfica & Documental & $\begin{array}{c}\text { Não } \\
\text { mencionado }\end{array}$ & $\begin{array}{c}\text { \% do } \\
\text { total }\end{array}$ \\
\hline Artigos & 3 & 10 & - & 4 & 89 & $51 \%$ \\
\hline Dissertações & 1 & - & 2 & 5 & 32 & $18 \%$ \\
\hline Teses & 1 & - & - & 1 & 22 & $12 \%$ \\
\hline Monografias & - & - & - & - & 3 & $1 \%$
\end{tabular}

FONTE: Scielo (2017), BDTD (2017); Portal de Periódicos Capes/MEC (2017), Google Scholar (2017). Organização: As autoras (2018)

No que diz respeito aos instrumentos quantitativos e qualitativos utilizados e que foram mencionados nos trabalhos, estes se encontram detalhados nas tabelas 9 e 10 respectivamente: 
TABELA 9: INSTRUMENTOS QUANTITATIVOS

\begin{tabular}{c|l|l|l}
$\begin{array}{c}\text { Instrumentos } \\
\text { Quantitativos }\end{array}$ & Artigos & Teses & Dissertações \\
\hline $\begin{array}{c}\text { Análise de Cluster K- } \\
\text { means }\end{array}$ & - & - & 1 \\
\hline Checklist & - & - & 1 \\
\hline $\begin{array}{c}\text { Amostra Aleatória } \\
\text { Estratificada }\end{array}$ & 2 & & \\
\hline $\begin{array}{c}\text { Amostra Não } \\
\text { Probabilística por } \\
\text { Conveniência }\end{array}$ & - & 1 & - \\
\hline Questionários & 7 & & \\
\hline Dados secundários & 10 & 3 & 9
\end{tabular}

FONTE: Scielo (2017), BDTD (2017); Portal de Periódicos Capes/MEC (2017), Google Scholar (2017). Organização: As autoras (2018)

TABELA 10: INSTRUMENTOS QUALITATIVOS

\begin{tabular}{c|l|l|l}
$\begin{array}{l}\text { Instrumentos } \\
\text { Qualitativos }\end{array}$ & Artigos & Teses & Dissertações \\
\hline Workshop & 1 & - & - \\
\hline $\begin{array}{c}\text { Observação } \\
\text { assistemática }\end{array}$ & - & - & 1 \\
\hline Observação sistemática & 1 & - & - \\
\hline História oral & & 1 & 2 \\
\hline Análise de conteúdo & 1 & 1 & 1 \\
\hline $\begin{array}{c}\text { Análise de fotografias } \\
\text { aéreas }\end{array}$ & - & - & 1 \\
\hline Observação in loco & 6 & - & 2 \\
\hline Registro fotográfico & 8 & 4 & 7 \\
\hline Pesquisa de campo & 8 & 9 & 3 \\
\hline Mapeamento & 2 & 7 & 1 \\
\hline Análise de documentos & & & \\
\hline $\begin{array}{c}\text { Entrevistas } \\
\text { semiestruturadas }\end{array}$ & 23 & 9 & 24 \\
\hline $\begin{array}{c}\text { Levantamento } \\
\text { bibliográfico }\end{array}$ & 36 & 10 & 29
\end{tabular}

FONTE: Scielo (2017), BDTD (2017); Portal de Periódicos Capes/MEC (2017), Google Scholar (2017). Organização: As autoras (2018)

Outro aspecto destacado são as qualificações Qualis-Capes dos periódicos das três principais áreas que realizaram publicações sobre a temática - Geografia, Turismo e Arquitetura e Urbanismo. Em seguida, procede-se o detalhamento das avaliações recebidas pelos periódicos que apresentaram ou não lacunas metodológicas (Tabelas 10 e 11): 
TABELA 10: AVALIAÇÃO QUALIS-CAPES DOS PERIÓDICOS POR ÁREA TEMÁTICA

\begin{tabular}{|c|c|c|c|c|c|c|}
\hline \multicolumn{3}{|c|}{ Total de periódicos avaliados na Plataforma Sucupira } & \multicolumn{4}{|c|}{ Artigos apresentados em eventos } \\
\hline \multicolumn{3}{|c|}{86} & & \multicolumn{2}{|r|}{20} & \\
\hline \multicolumn{7}{|c|}{ Áreas do conhecimento e qualificações CAPES } \\
\hline Qualificações & Geografia & $\%$ do total & Turismo & $\%$ do total & $\begin{array}{c}\text { Arquitetura e } \\
\text { Urbanismo }\end{array}$ & $\%$ do total \\
\hline $\mathrm{A} 2$ & 9 & $10 \%$ & - & - & - & - \\
\hline B1 & 6 & $6 \%$ & 3 & $3 \%$ & 1 & $1 \%$ \\
\hline $\mathrm{B} 2$ & 8 & $9 \%$ & 4 & $4 \%$ & 1 & $1 \%$ \\
\hline B3 & 6 & $6 \%$ & 8 & $9 \%$ & 6 & $6 \%$ \\
\hline B4 & 7 & $8 \%$ & 5 & $5 \%$ & 4 & $4 \%$ \\
\hline B5 & 9 & $10 \%$ & 4 & $4 \%$ & 3 & $3 \%$ \\
\hline $\mathrm{C}$ & - & - & 1 & $1 \%$ & 2 & $2 \%$ \\
\hline
\end{tabular}

FONTE: Scielo (2017), BDTD (2017); Portal de Periódicos Capes/MEC (2017), Google Scholar (2017). Plataforma

Sucupira - Qualis Periódicos (2019). Organização: As autoras (2019)

\section{Considerações finais}

As segundas residências turísticas têm suscitado o interesse acadêmico dos mais variados campos do saber, cujos estudos têm se concentrado nas ressonâncias positivas e/ou negativas desse fenômeno. O presente estudo de caráter bibliométrico identificou uma quantidade considerável de produções relacionadas ao turismo de segundas residências. Observa-se que eles têm contribuído para elevar a visibilidade da temática no cenário acadêmico brasileiro, tendo em vista que as residências secundárias constituem o cerne da urbanização de parte significativa dos espaços litorâneos. Em muitos casos, destinos tropicais transformados em mercadorias globais de turismo, nos quais o capital imobiliário exerce força central. Portanto, lançar atenção sobre as especificidades desse fenômeno contribui para clarificar as diversas facetas que o compõem. Particularmente, constitui um fator necessário para que se compreenda a dinâmica territorial.

A pesquisa investigou as produções acadêmicas sobre a temática entre as décadas 1990 e 2017. Dentro desse período, o cenário turístico do litoral brasileiro perpassou por metamorfoses em função da forte especulação imobiliária que se projeta sobre as principais áreas litorâneas, em concomitância com o aumento dos fluxos, ampliação dos espaços e destinação das comunidades do litoral para implantação de meios de hospedagem. Os conteúdos presentes nas publicações corroboraram tal realidade, evidenciando que o turismo e a segunda residência são fenômenos que explicitam contradições e conflitos de interesse, dentro de um contexto de fortes desníveis socioeconômicos e assimetrias nas relações de poder. O território, como elemento que transcende a 
expressão material, demonstrou-se um ponto medular nas discussões acerca do fenômeno, em que pese a multiplicidade de impactos sociais, econômicos, culturais e ambientais tanto positivos quanto negativos derivados do fenômeno turístico.

Observou-se que a maior parte das publicações advém da pós-graduação, com números significativos de produções oriundas de estudos de mestrado e doutorado, evidenciando a baixa expressividade da graduação no âmbito da pesquisa. No tocante à metodologia, inobstante tenha se identificado múltiplos tipos de instrumentos de pesquisa, observou-se diversos hiatos nas classificações metodológicas no que se refere à abordagem, aos objetivos e aos procedimentos. As lacunas nas classificações metodológicas foram observadas, em especial em artigos e dissertações. Em 20\% dos artigos não havia classificação metodológica e em 35\% deles havia classificação metodológica incompleta. No tocante às teses, apenas $1 \%$ apresentou completude classificatória, com 9,8\% apresentando classificação metodológica incompleta. Em apenas 3\% das dissertações havia classificação metodológica completa, com 17\% apresentando incompleta e 3\% sem classificação.

No que tange às limitações do estudo, destaca-se a delimitação do recorte territorial litorâneo que concede uma visão parcial da dinâmica relativa à segunda residência. Para pesquisas futuras da mesma natureza, recomenda-se replicar para as áreas interioranas, que também são alvo do fenômeno da segunda residência. Além disso, indica-se o levantamento das publicações internacionais como forma de dimensionar as várias nuances que integram o fenômeno não apenas pela perspectiva nacional.

Neste contexto, destaca-se que diante da clara indissociabilidade existente entre o conhecimento e a informação registrada, a bibliometria se apresenta como uma ferramenta de incontestável relevância na identificação de progressos e lacunas na produção científica conforme destacam Costa (et. al, 2012). Tal identificação, todavia, não se reveste de uma roupagem de puro criticismo, mas sim, simboliza um contributo para o necessário e permanente exercício de aperfeiçoamento na trajetória da construção do saber.

\section{Referências}

ALBUQUERQUE, I, S. Turismo de segunda residência: avanços e impactos no território potiguar. Seminário Nacional Governança Urbana e Desenvolvimento Metropolitano. Natal/RN. 2010.

ACSELRAD, H. Ambientalização das lutas sociais - o caso do movimento por justiça ambiental. Estudos avançados 24 (68), 2010. 
AUGÉ, M. Não lugares. Editora Papirus. 2012. Tradução de Maria Lúcia Pereira.

ARAÚJO, C.A.. Bibliometria: evolução histórica e questões atuais. Em Questão, Porto Alegre, V.12, N.1, p. 11-32.

ASSIS, L. F. Turismo de segunda residência: a expressão espacial do fenômeno e as possibilidades de análise geográfica. Revista Território - Rio de Janeiro, Ano VII - $\mathrm{n}^{\circ} 11,12$ e 13 - set/out. 2003.

BARBOSA, et. al. Turismo: Inovações da Pesquisa na América Latina. V Seminário de Pesquisa em Turismo do MERCOSUL (SeminTUR). 2008.

BDTD. Biblioteca Digital Brasileira de Teses e Dissertações. Disponível em http://bdtd.ibict.br/vufind/.

BUFREM, L.; PRATES, Y. O saber científico registrado e as práticas de mensuração da informação. Ci. Inf., Brasília, v. 34, n. 2, p 9-25, 2005.

CHUEKE, G, V; AMATUCCI, M. O que é bibliometria? Uma introdução ao fórum. Revista Eletrônica de Negócios Internacionais. São Paulo, v.10, n.2. maio 2015.

CORIOLANO, L, N, M, T. O turismo nos discursos, nas políticas e no combate à pobreza. $1^{\circ}$ Edição. Editora Annablume. 2006.

COSTA et. Al. A Bibliometria e a avaliação da produção científica: indicadores e ferramentas. Actas. Congresso Nacional de Bibliotecários, arquivistas e documentalistas. N. 11. 2012.

COTTYN, I. The spatial and socio-cultural impacts of second home development. A case study on Franschhoek, South Africa. Master Thesis, Utrecht University, 2011.

FERREIRA, I.C.R. (2006) "Os impactos sociais, econômicos e culturais do turismo em Guaramiranga - CE”. Revista Turismo, Fortaleza, 2006.

GERHARDT, T, A.; SILVEIRA, D, T. Métodos de pesquisa. $1^{\circ}$ Edição. 2009.

GIL, A. Como elaborar projetos de pesquisas. São Paulo. Atlas. 2002.

HAESBAERT, R. Dos múltiplos territórios à multiterritorialidade. Porto Alegre, Setembro. 2004.

HAESBAERT, R.; LIMONAD, E. O território em tempos de globalização. Etc. Revista Eletrônica de Ciências Sociais Aplicadas e outras coisas. 2007, n. 2 (4), v. 1.

HILU, L.; GISI, M, L. Produção científica no Brasil - Um comparativo entre as universidades públicas e privadas. X Congresso Nacional de Educação - Educere. Curitiba. 2011.

IBGE. Atlas geográfico das zonas costeiras e oceânicas do Brasil. Rio de Janeiro. 2011.

MARTINS, H, H, T, S. Metodologia qualitativa de pesquisa. Educação e Pesquisa, São Paulo, v. 30, n. 2, p. 289-300. 2004. 
MARJAVAARA, R. Second Home Tourism: The Root to Displacement in Sweden? Doctoral Dissertation. Departament of Social and Economic Geography. Umea University, Sweden. 2008.

LOPES, et. al. Avaliação de políticas públicas de turismo: uma análise bibliométrica dos periódicos de turismo. Revista Turismo Em Análise. V. 22. N. 3. 2011.

MEDINA, J, C, C. Re-construcción de la cultura y del espacio turístico. In MDS Brasileiro, JCC Medina, LN Coriolano (orgs). Turismo, cultura e desenvolvimento. [online]. 2012. EDUEPB, Campina Grande, 233 pp.

OLIVEIRA, M, F, S.; OLIVEIRA, O, J, R. Estado e turismo: trajetórias do caso baiano. Caderno Virtual de Turismo - Rio de Janeiro, v. 12, n. 3, p. 384-398, dez. 2012.

PAULA, D.P. Desenvolvimento do turismo de sol e praia em destinos tropicais: o caso do litoral de Fortaleza. Brazilian Geographical Journal. 2012.

PEREIRA et. al. Lazer na praia. Segunda residência e imobiliário turístico no nordeste. Fortaleza. 2016. Edições UFC.

Portal de Periódicos Capes/MEC. Disponível em http://www.periodicos.capes.gov.br/. Google Scholar. Disponível em https://scholar.google.com.br/.

Plataforma Sucupira. Disponível em https://sucupira.capes.gov.br/sucupira/public/consultas/coleta/veiculoPublicacaoQualis/listaConsult aGeralPeriodicos.jsf

SCIELO. Scientific Electronic Library Online. Disponível em http://www.scielo.org/php/index.php.

SANTOS, M. O dinheiro e o território. Universidade de São Paulo. GEOgraphia - ano 1, no 1 1999.

SANTOS, P.P; VILAR, J.W.C. Território e conflitos ambientais do turismo de segunda residência na APA litoral Sul (SE). Ateliê Geográfico - Goiânia - GO, v.7, n.2, pp. 44-70, ago/2013.

SILVA, et. al. Megaeventos e turismo: um estudo bibliométrico dos periódicos brasileiros de turismo. Turismo Visão e Ação. V. 18, n. 3. 2016.

TALAVERA, A, S. O turismo na sociedade de consumo: Aportes antropológicos à figuração do subsistema estático. 26º Reunião Brasileira de Antropologia. Bahia, Brasil. 2008.

TRIGO, L, G, G. A sociedade pós-industrial e o profissional em turismo. $7^{\circ}$ Edição. Papirus Editora. 1998.

UNWTO. Organizacion Mundial del Turismo. Entender el turismo: Glosario Basico. 2007. 
XAVIER, et. al. A relação entre redes e turismo: uma análise bibliométrica sobre a emergência de um novo paradigma no planejamento turístico. Revista Turismo e Sociedade. V. 5. N. 2.

Artigo recebido em 06/03/2019. Aceito para publicação em 12/06/2019. 